\title{
Serum Triglyceride Level: A Predictor of Complications and Outcomes in Acute Pancreatitis?
}

\author{
Hassan Tariq, Vinaya Gaduputi, Richard Peralta, Naeem Abbas, Suresh Kumar Nayudu, \\ Phyo Thet, Tin Zaw, Shirley Hui, and Sridhar Chilimuri
}

Department of Medicine, Bronx-Lebanon Hospital Center, 1650 Selwyn Avenue, Suite No. 10C, Bronx, NY 10457, USA

Correspondence should be addressed to Hassan Tariq; htariq@bronxleb.org

Received 6 October 2015; Accepted 6 November 2015

Copyright (C) 2016 Hassan Tariq et al. This is an open access article distributed under the Creative Commons Attribution License, which permits unrestricted use, distribution, and reproduction in any medium, provided the original work is properly cited.

\begin{abstract}
Aim. To study serum triglyceride level as a predictor of complications and outcomes in acute pancreatitis. Methods. In this retrospective observational study, 582 patients admitted with acute pancreatitis, who had serum triglyceride levels measured within the first 24 hours, were divided into two groups. The study group consisted of patients with a triglyceride level $\geq 2.26 \mathrm{mmol} / \mathrm{L}$ (group 2) and the control group consisted of triglyceride level of $<2.26 \mathrm{mmol} / \mathrm{L}$ (group 1). We collected data for baseline demographics, laboratory values, incidence of complications (local and systemic), admission to the intensive care unit (ICU), ICU length of stay, length of total hospital stay, and death in the two groups. Results. A triglyceride level of $\geq 2.26 \mathrm{mmol} / \mathrm{L}$ was found to be an independent predictor of developing altered mental status ( $p: 0.004)$, pancreatic necrosis $(p: 0.001)$, acute respiratory distress syndrome ( $p: 0001)$, systemic Inflammatory response syndrome ( $p: 0.001)$, acute kidney injury ( $p: 0.001)$, hospital length of stay (LOS) ( $p$ : 0.002), admission to intensive care unit (ICU) ( $p$ : 0.002), and ICU LOS ( $p$ : 0.003). Conclusion. A triglyceride level of $\geq 2.26 \mathrm{mmol} / \mathrm{L}$ on admission in acute pancreatitis is an independent predictor of developing local and systemic complications, hospital LOS, admission to ICU, and ICU LOS.
\end{abstract}

\section{Introduction}

Acute pancreatitis, an inflammatory disorder of the pancreas, is the most frequent cause of admission to hospital due to gastrointestinal disorders in the USA [1,2]. With an annual incidence ranging from 4.9 to 35 per 100,000 population, approximately 15 to 25 percent of all patients with acute pancreatitis (AP) develop severe AP [3]. The mortality ranges from 3 percent in patients with interstitial edematous pancreatitis to 17 percent among patients with pancreatic necrosis [4, 5]. Between 1988 and 2003, mortality from acute pancreatitis decreased from 12 percent to 2 percent, according to a large epidemiologic study [3]. However, mortality rates remain much higher in subgroups of patients with severe disease. The ability to predict the severity of acute pancreatitis can help identify patients at increased risk for morbidity and mortality, therefore helping clinicians to make an early decision to triage these patients to intensive care units as well as selection of patients for specific interventions.

A multitude of predictive models have been developed to predict the severity of acute pancreatitis (AP) based upon clinical, laboratory, and radiological parameters [6].
Serum triglyceride (TG) concentrations above $11 \mathrm{mmol} / \mathrm{L}$ (1000 mg/dL) can precipitate attacks of acute pancreatitis [7]. Hypertriglyceridemia (HTG) accounts for 1 to 4 percent of cases of acute pancreatitis $[8,9]$. On the other hand, HTG is commonly present at the early stage of non-HTG-induced AP and its clinical significance remains unclear [10].

The relationship between the elevated TG level and severity of non-HTG-induced AP is not well established. Some studies reported that an elevated triglyceride level in non-HTG-induced AP was accompanied by more severe disease [11, 12]. However, other studies did not show any significant relationship between an elevated TG level and the severity or prognosis of AP patients [13].

The impact of different levels of HTG on the severity and complications of AP has not been clearly defined. In this study, we aimed to analyze the influence of elevated triglyceride level in acute pancreatitis (AP) and its prognosis.

\section{Methods}

This is a retrospective single center observational study. The period of study was 6 years between October 1, 2008, and 
October 31, 2014. The study was performed according to the Declaration of Helsinki and was approved by the Institution Review Board (IRB) of Bronx Lebanon hospital center.

2.1. Patient Selection. The data was collected from the electronic medical records of patients and tabulated in Microsoft Excel $^{\circledR}$ (Microsoft Corp, Redmond, WA, USA). Patients $\geq 18$ years of age admitted to our hospital with the diagnosis of acute pancreatitis (AP), who had serum triglyceride levels measured within the first 24 hours of admission, were included in the study population. The diagnosis of AP was made when any two of the following three criteria were met: classic abdominal pain; elevation of amylase and/or lipase three times the upper limit of normal; and radiographic evidence of acute pancreatitis. The initial study population consisted of 686 patients. Patients with end stage renal disease, those with chronic kidney disease and those with missing information/data were excluded from the study. A total of 582 patients were finally included and divided into two study groups.

2.2. Group Division. The study group consisted of patients with a triglyceride level $\geq 2.26 \mathrm{mmol} / \mathrm{L}$ ( $\geq 200 \mathrm{mg} / \mathrm{dL}$ ) (group 2 ) and the control group consisted of triglyceride level of $<2.26 \mathrm{mmol} / \mathrm{L}(<200 \mathrm{mg} / \mathrm{dL}$ ) (group 1). All the values were measured within the first 24 hours of presentation.

2.3. Data Collection. Baseline demographic data including age, gender, and ethnicity were collected for all patients in the study. We collected the data on patients' Body mass indices (BMI), vital signs on admission, complete blood count, complete metabolic panel, D-dimers, Liver function test, serum amylase, serum lipase, and serum triglyceride levels. We calculated the incidence of local and systemic complications including acute respiratory distress syndrome (ARDS), shock, pancreatic necrosis, and acute kidney injury (AKI), among the two study groups. We also collected the data on the antibiotic usage during hospitalization, need for surgical or interventional radiological intervention, admission to the intensive care unit (ICU), ICU length of stay (LOS), length of total hospital stay, and death in the two groups.

2.4. Definitions and Criteria. The classification of AP severity was based on the 2012 revision of the Atlanta Classification [14]. Severe AP was defined by the presence of persistent $(\geq 48 \mathrm{~h})$ organ failure and/or death. Moderately severe acute pancreatitis is characterized by the presence of transient $(<48 \mathrm{~h})$ organ failure or local or systematic complications in the absence of persistent organ failure. Mild AP is defined by the absence of organ failure and/or pancreatic necrosis.

Complications were defined as follows: shock as a systolic blood pressure of less than $90 \mathrm{~mm}$ of $\mathrm{Hg}$, systemic inflammatory response syndrome (SIRS) defined by the presence of $\geq 2$ of the following clinical findings: body temperature higher than $38^{\circ} \mathrm{C}$ or lower than $36^{\circ} \mathrm{C}$, heart rate higher than $90 / \mathrm{min}$, hyperventilation evidenced by respiratory rate higher than $20 / \mathrm{min}$, or a $\mathrm{PaCO}_{2}$ of less than $4.26 \mathrm{kPa}(32 \mathrm{~mm}$ of $\mathrm{Hg}$ ), white blood cell count higher than $12,000 \times 10^{9} / \mathrm{L}$ or lower than $4,000 \times 10^{9} / \mathrm{L}$, sepsis defined as SIRS associated with infection, severe sepsis as sepsis associated with organ dysfunction, hypoperfusion, or hypotension, and septic shock as sepsis with arterial hypotension despite adequate fluid resuscitation. Pancreatic necrosis is defined as diffuse or focal areas of nonviable pancreatic parenchyma $>3 \mathrm{~cm}$ in size or $>30 \%$ of the pancreas. Acute kidney injury (AKI) was defined as increase in the serum creatinine concentration of $\geq 26.5 \mu \mathrm{mol} / \mathrm{L}(\geq 0.3 \mathrm{mg} / \mathrm{dL})$ from baseline; a percentage increase in the serum creatinine concentration of $\geq 50$ percent; or oliguria of $<0.5 \mathrm{~mL} / \mathrm{kg}$ per hour for more than six hours.

The Bedside Index for Severity in Acute Pancreatitis (BISAP) score that predicts clinical outcomes in patients with AP was calculated using the variables of $\mathrm{BUN}>8.92 \mathrm{mmol} / \mathrm{L}$ ( $>25 \mathrm{mg} / \mathrm{dL}$ ), impaired mental status, $\geq$ SIRS criteria, age $>60$, and presence of pleural effusion with each variable assigned one point if present [15].

2.5. Statistical Methods. Statistical analysis was performed with IBM SPSS 20 (Statistical Packages for the Social Sciences). Results were reported as the means with standard deviation for most variables and 95\% confidence intervals or percentages for some variables. For comparison of continuous variables between the two groups, we used the independent sample tests $t$-test. Dichotomous variables were compared by chi-square analysis using the Pearson test. Subsequently, we used a multivariate analysis of covariance (MANCOVA) model to determine whether a triglyceride of $\geq 2.26 \mathrm{mmol} / \mathrm{L}(\geq 200 \mathrm{mg} / \mathrm{dL})$ was independently associated with various complications in AP. Variables with $p$ value $<0.05$ in the univariate analysis were included in the multivariate model. The model was thus adjusted for relevant risk factors for AP severity, namely, advanced age $(\geq 60$ years), sex, body mass index $\geq 30\left(\mathrm{~kg} / \mathrm{m}^{2}\right)$ (class I obesity), and diabetic status. Linear regression and multiple regression analysis were used to find statistical significant predictors of complications between groups. A two-tailed value of $p<0.05$ was considered statistically significant.

\section{Results}

3.1. Comparison of General Information of Patients. There were 582 AP patients included in the study, out of which $482 \mathrm{had}$ a triglyceride level of $<2.26 \mathrm{mmol} / \mathrm{L}$ (group 1) and $100 \mathrm{had}$ a triglyceride level of $\geq 2.26 \mathrm{mmol} / \mathrm{L}$ (group 2 ). This cohort included 256 men and 226 women. The male to female ratio in group 1 was lower as compared to group 2 (1.13 versus $2.12, p: 0.004)$. The mean BMI was similar in both the groups $(28.7 \pm 7.6$ versus $27.25 \pm 5.9, p: 0.086)$. There were more cases of acute biliary pancreatitis in group 1 and more cases of alcoholic pancreatitis in group 2. Baseline characteristics and etiology of pancreatitis in both the groups are shown in Table 1 .

Patients with triglyceride level of $\geq 2.26 \mathrm{mmol} / \mathrm{L}$ (group 2) had a higher rate of acute kidney injury on admission. Other laboratory parameters on admission and peak creatinine recorded during the admission are tabulated in Table 2. 
TABLE 1: Population baseline characteristics.

\begin{tabular}{|c|c|c|c|}
\hline Characteristic & $\begin{array}{c}\text { Triglyceride }<2.26 \mathrm{mmol} / \mathrm{L} \\
(<200 \mathrm{mg} / \mathrm{dL}) \\
(N: 482)\end{array}$ & $\begin{array}{c}\text { Triglyceride } \geq 2.26 \mathrm{mmol} / \mathrm{L} \\
(\geq 200 \mathrm{mg} / \mathrm{dL}) \\
(N: 100)\end{array}$ & $p$ value \\
\hline Age, years* & $49 \pm 14$ & $50.5 \pm 13$ & 0.390 \\
\hline Sex, number (\%) & & & 0.004 \\
\hline Male & $256(53)$ & $68(68)$ & \\
\hline Female & $226(47)$ & $32(32)$ & \\
\hline $\mathrm{BMI} \mathrm{kg} / \mathrm{m}^{2^{*}}$ & $28.7 \pm 7.6$ & $27.25 \pm 5.9$ & 0.086 \\
\hline \multicolumn{4}{|c|}{ Pancreatitis etiology, number (\%) } \\
\hline Biliary & $140(29)$ & $21(21)$ & 0.001 \\
\hline Alcoholism & $156(32)$ & $34(34)$ & 0.001 \\
\hline Hypertriglyceridemia & $0(0)$ & $18(18)$ & 0.001 \\
\hline Post-ERCP & $5(1)$ & $1(1)$ & 0.001 \\
\hline Unknown + other $^{\beta}$ & $181(37)$ & $26(26)$ & 0.001 \\
\hline \multicolumn{4}{|c|}{ Comorbidities, number $(\%)^{\ddagger}$} \\
\hline Hypertension & $298(61)$ & $69(69)$ & 0.097 \\
\hline Diabetes mellitus & $139(29)$ & $45(45)$ & 0.001 \\
\hline $\mathrm{CHF}$ & $25(5)$ & $8(8)$ & 0.188 \\
\hline Cirrhosis & $22(4.5)$ & $3(3)$ & 0.352 \\
\hline HIV & $67(14)$ & $13(13)$ & 0.481 \\
\hline Smoker & $205(42)$ & $42(42)$ & 0.503 \\
\hline Alcoholism & 267 (55) & 59 (59) & 0.221 \\
\hline
\end{tabular}

* Plus-minus are means with \pm SD.

${ }^{\ddagger}$ Percentage may not add up to 100 because some patients had more than one disorder or risk factor.

B: cases of Pancreatitis in which a cause could not be established or were caused by other etiologies such as hypercalcemia, drugs, trauma, pancreatic divisum, or autoimmune pancreatitis.

3.2. Incidence of Complications in the Two Groups. Patients in group 2 had a higher rate of altered mental status on presentation as compared to group 1 (13\% versus $5.1 \% p$ : $0.007)$. There was no significant difference between the two groups in the incidence of pleural effusion $(12.6 \%$ versus $17 \% p: 0.259)$ and shock $(2.69 \%$ versus $5 \% p: 0.213)$. The incidence of pancreatic necrosis ( $12 \%$ versus $3.11 \% p$ : 0.001$)$ as well as acute respiratory distress syndrome (7\% versus $1.45 \% p: 0.005)$ was higher in group 2 as compared to group 1. We observed in our study that the incidence of acute kidney injury during the hospitalization was significantly higher in patients with a triglyceride level of $\geq 2.26 \mathrm{mmol} / \mathrm{L}$ on admission (52\% versus $34.85 \%$ p: 0.001 ). Patients in group 2 had a significantly higher incidence of SIRS (31\% versus $16.8 \%, p: 0.002$ ) as compared to group 1.

The hospital length of stay (LOS) in days $(7.3 \pm 4.4$ versus $10.9 \pm 7.8 p$ : 0.002), incidence of admission to the intensive care unit (22.4\% versus $37 \%$, $p: 0.003)$, and the ICU length of stay in days $(1.1 \pm 0.3$ versus $2.2 \pm 0.5, p$ : 0.003$)$ were higher in group 2 as compared to group 1.

The rates of gastrointestinal bleeding need for surgical intervention, antibiotic use, and death between the two groups were not statistically different. Incidence of complications in the two study groups is tabulated in Table 3.
3.3. Multivariate Analysis. We performed multivariate analysis using multivariate analysis of covariance (MANCOVA) model adjusting for relevant risk factors associated with AP severity, namely, advanced age ( $\geq 60$ years), sex, body mass index $\geq 30$ (class I obesity), and diabetic status (Wilks Lambda: 0.001). The results are tabulated in Table 4.

Patients in group 2 were found to have a higher BISAP score on admission ( $p$ : 0.002) (Table 5). Similarly, in group 2 there was a higher incidence of SIRS on admission $(31 \%$ versus $16.73 p$ : 0.011) (Table 6).

3.4. Linear Regression Analysis. A triglyceride level of $\geq 2.26 \mathrm{mmol} / \mathrm{L}$ ( $\geq 200 \mathrm{mg} / \mathrm{dL}$ ) was found to be an independent predictor of developing altered mental status ( $\beta$ : $0.119,95 \%$ CI $0.09-0.32, p$ : 0.004$)$, pancreatic necrosis ( $\beta$ : $0.160,95 \%$ CI $0.08-0.24, p$ : 0.001$)$, ARDS ( $\beta$ : $0.137,95 \%$ CI $0.11-0.18, p$ : $0001), \operatorname{SIRS}(\beta: 0.136,95 \%$ CI $0.09-0.5 p$ : 0.001), acute kidney injury $(\beta$ : $0.145,95 \%$ CI $0.08-0.7, p: 0.001)$, hospital length of stay $(\beta$ : $0.127,95 \%$ CI $0.11-0.14, p: 0.002)$, admission to ICU ( $\beta: 0.127,95 \%$ CI $0.05-0.6, p: 0.002)$, and ICU LOS $(\beta: 0.125$, 95\% CI 0.09-0.14, p: 0.003).

3.5. Multiple Regression Analysis. To validate our results from linear regression, a model of multiple linear regression 
TABLE 2: Laboratory test values on admission.

\begin{tabular}{|c|c|c|c|}
\hline & $\begin{array}{c}\text { Triglyceride }<2.26 \mathrm{mmol} / \mathrm{L} \\
(<200 \mathrm{mg} / \mathrm{dL}) \\
(N: 482)\end{array}$ & $\begin{array}{c}\text { Triglyceride } \geq 2.26 \mathrm{mmol} / \mathrm{L} \\
(\geq 200 \mathrm{mg} / \mathrm{dL}) \\
(N: 100)\end{array}$ & $p$ value \\
\hline Hematocrit & $0.39 \pm 0.058$ & $0.40 \pm 0.062$ & 0.099 \\
\hline WBC $\left(\times 10^{9} / \mathrm{L}\right)$ & $10.1 \pm 4.9$ & $10.9 \pm 47$ & 0.097 \\
\hline Platelets $\left(\times 10^{9} / \mathrm{L}\right)$ & $229.6 \pm 93.2$ & $218.7 \pm 95.6$ & 0.291 \\
\hline Sodium $(\mathrm{mmol} / \mathrm{L})$ & $135.8 \pm 4.3$ & $133.5 \pm 6.2$ & 0.001 \\
\hline Potassium (mmol/L) & $4.1 \pm 0.6$ & $4.2 \pm 0.7$ & 0.013 \\
\hline Chloride $(\mathrm{mmol} / \mathrm{L})$ & $102.3 \pm 6.8$ & $100.6 \pm 7.2$ & 0.021 \\
\hline Bicarbonate $(\mathrm{mmol} / \mathrm{L})$ & $24.3 \pm 4.3$ & $22.1 \pm 5.5$ & 0.001 \\
\hline $\mathrm{BUN}(\mathrm{mmol} / \mathrm{L})$ & $5.21 \pm 4.17$ & $8.67 \pm 4.60$ & 0.004 \\
\hline Creatinine $(\mu \mathrm{mol} / \mathrm{L})$ on admission & $77.8 \pm 61.9$ & $141.44 \pm 106.1$ & 0.001 \\
\hline Maximum creatinine $(\mu \mathrm{mol} / \mathrm{L})$ & $97.24 \pm 70.7$ & $167.9 \pm 61.9$ & 0.001 \\
\hline Calcium (mmol/L) & $2.35 \pm 0.3$ & $2.35 \pm 0.2$ & 0.663 \\
\hline AST $(\mu \mathrm{kat} / \mathrm{L})$ & $2.22 \pm 0.66$ & $2.20 \pm 0.37$ & 0.965 \\
\hline $\operatorname{ALT}(\mu \mathrm{kat} / \mathrm{L})$ & $2.00 \pm 0.64$ & $1.73 \pm 0.35$ & 0.482 \\
\hline Bilirubin $(\mu \mathrm{mol} / \mathrm{L})$ & $22.23 \pm 10.26$ & $29.08 \pm 6.84$ & 0.105 \\
\hline Protein (g/L) & $74 \pm 8$ & $75 \pm 12$ & 0.241 \\
\hline Albumin $(g / L)$ & $41.4 \pm 6$ & $40.1 \pm 7$ & 0.083 \\
\hline INR & $1.1 \pm 0.3$ & $1.1 \pm 0.3$ & 0.664 \\
\hline D-dimer $(\mathrm{nmol} / \mathrm{L})$ & $1365.16 \pm 479.15$ & $3942.72 \pm 1379.95$ & 0.037 \\
\hline HbAlc & $0.073 \pm 0.025$ & $0.088 \pm 0.028$ & 0.001 \\
\hline Amylase $(\mu$ kat/L) & $8.53 \pm 0.65$ & $7.16 \pm 0.92$ & 0.346 \\
\hline Lipase $(\mu \mathrm{kat} / \mathrm{L})$ & $17.3 \pm 1.06$ & $12.2 \pm 1.70$ & 0.017 \\
\hline
\end{tabular}

TABLE 3: Incidence of complications in the two study groups.

\begin{tabular}{|c|c|c|c|}
\hline Complication & $\begin{array}{c}\text { Triglyceride }<2.26 \mathrm{mmol} / \mathrm{L} \\
(<200 \mathrm{mg} / \mathrm{dL}) \\
(N: 482)\end{array}$ & $\begin{array}{c}\text { Triglyceride } \geq 2.26 \mathrm{mmol} / \mathrm{L} \\
(\geq 200 \mathrm{mg} / \mathrm{dL}) \\
(N: 100)\end{array}$ & $p$ value \\
\hline Alteration in mental status & $25(5.1)$ & $13(13)$ & 0.007 \\
\hline SIRS & $81(16.8)$ & $31(31)$ & 0.002 \\
\hline Pleural effusion & $61(12.6)$ & $17(17)$ & 0.259 \\
\hline Shock & $13(2.69)$ & $5(5)$ & 0.213 \\
\hline Pancreatic necrosis & $15(3.11)$ & $12(12)$ & 0.001 \\
\hline ARDS & $7(1.45)$ & $7(7)$ & 0.005 \\
\hline AKI & $168(34.85)$ & $52(52)$ & 0.001 \\
\hline LOS (days) ${ }^{*}$ & $7.3 \pm 4.4$ & $10.9 \pm 7.8$ & 0.002 \\
\hline ICU LOS (days) $^{*}$ & $1.1 \pm 0.3$ & $2.2 \pm 0.5$ & 0.003 \\
\hline Admission to ICU & $108(22.4)$ & $37(37)$ & 0.003 \\
\hline GI bleed & $9(1.86)$ & $2(2)$ & 0.59 \\
\hline IR or surgery & $63(13)$ & $14(14)$ & 0.452 \\
\hline Antibiotic use & $133(27.5)$ & $32(32)$ & 0.217 \\
\hline Death & $11(2.28)$ & $5(5)$ & 0.169 \\
\hline
\end{tabular}

* Plus-minus are means with \pm SD. 
TABLE 4: Multivariate analysis showing association of triglyceride level with complications after adjusting for advanced age, sex, obesity, and diabetic status.

\begin{tabular}{|c|c|c|c|}
\hline Complication & $\begin{array}{c}\text { Triglyceride }<2.26 \mathrm{mmol} / \mathrm{L} \\
(<200 \mathrm{mg} / \mathrm{dL}) \\
(N: 482)\end{array}$ & $\begin{array}{c}\text { Triglyceride } \geq 2.26 \mathrm{mmol} / \mathrm{L} \\
(\geq 200 \mathrm{mg} / \mathrm{dL}) \\
(N: 100)\end{array}$ & $p$ value \\
\hline Alteration in mental status & $25(5.1)$ & $13(13)$ & 0.001 \\
\hline SIRS & $81(16.8)$ & $31(31)$ & 0.047 \\
\hline Pancreatic necrosis & $15(3.11)$ & $12(12)$ & 0.002 \\
\hline ARDS & $7(1.45)$ & $7(7)$ & 0.002 \\
\hline AKI & $168(34.85)$ & $52(52)$ & 0.001 \\
\hline LOS (days) ${ }^{*}$ & $7.3 \pm 4.4$ & $10.9 \pm 7.8$ & 0.016 \\
\hline ICU LOS (days)* & $1.1 \pm 0.3$ & $2.2 \pm 0.5$ & 0.009 \\
\hline Admission to ICU & $108(22.4)$ & $37(37)$ & 0.002 \\
\hline
\end{tabular}

${ }^{*}$ Plus-minus are means with \pm SD.

TABle 5: Incidence of the Bedside Index for Severity in Acute Pancreatitis (BISAP) score in the two groups.

\begin{tabular}{|c|c|c|c|c|c|c|c|}
\hline & \multicolumn{6}{|c|}{ Number of BISAP score variables present in both groups. } & \multirow{2}{*}{ Total } \\
\hline & 0 & 1 & 2 & 3 & 4 & 5 & \\
\hline $\begin{array}{l}\text { Triglyceride }<2.26 \mathrm{mmol} / \mathrm{L} \\
(<200 \mathrm{mg} / \mathrm{dL}) \\
(N: 482)\end{array}$ & $260(53.9)$ & $150(31.1)$ & $53(10.9)$ & $13(2.6)$ & $4(0.82)$ & $2(0.041)$ & 482 \\
\hline $\begin{array}{l}\text { Triglyceride } \geq 2.26 \mathrm{mmol} / \mathrm{L} \\
(\geq 200 \mathrm{mg} / \mathrm{dL}) \\
(N: 100)\end{array}$ & $35(35)$ & $37(37)$ & $16(16)$ & $7(7)$ & $4(4)$ & $1(1)$ & 100 \\
\hline Total & 295 & 187 & 69 & 20 & 8 & 3 & 582 \\
\hline
\end{tabular}

TABLE 6: Incidence of systemic inflammatory response syndrome (SIRS) in the two groups.

\begin{tabular}{|c|c|c|c|c|c|c|}
\hline & \multicolumn{5}{|c|}{ SIRS variables present in both groups. } & \multirow{2}{*}{ Tota } \\
\hline & 0 & 1 & 2 & 3 & 4 & \\
\hline $\begin{array}{l}\text { Triglyceride }<2.26 \mathrm{mmol} / \mathrm{L} \\
(<200 \mathrm{mg} / \mathrm{dL}) \\
(N: 482)\end{array}$ & $212(43.9)$ & $189(39.2)$ & $62(12.8)$ & $16(3.31)$ & $3(0.62)$ & 482 \\
\hline $\begin{array}{l}\text { Triglyceride } \geq 2.26 \mathrm{mmol} / \mathrm{L} \\
(\geq 200 \mathrm{mg} / \mathrm{dL}) \\
(N: 100)\end{array}$ & $37(37)$ & $32(32)$ & $20(20)$ & $9(9)$ & $2(2)$ & 100 \\
\hline Total & 249 & 221 & 82 & 25 & 5 & 582 \\
\hline
\end{tabular}

analysis was done using altered mental status, pancreatic necrosis, ARDS, SIRS, acute kidney injury, hospital length of stay, admission to ICU and ICU LOS as independent variable, and a triglyceride level of $\geq 2.26 \mathrm{mmol} / \mathrm{L}(\geq 200 \mathrm{mg} / \mathrm{dL})$ as dependent one, and we found an adjusted $R$ square of 0.145 , $p \leq 0.001, F=4.402 p \leq 0.001$.

\section{Discussion}

Many predictive models have been developed to identify patients at increased risk for morbidity and mortality from acute pancreatitis. The ideal predictor would be a single marker that can be reliably and rapidly measured with costeffectiveness while causing no discomfort to the patient [6]. Recent studies have suggested that triglyceride level $\geq 2.26 \mathrm{mmol} / \mathrm{L}$ in patients with acute pancreatitis increases the incidence of complications compared to normal triglyceride levels [16]. In our study, we aimed to study the serum triglyceride level as a marker that can predict the development of complications and the need for admission to ICU among patients admitted with acute pancreatitis. Although alcohol use is associated with elevated triglyceride levels [10], we did not find an increased percentage of individuals with triglyceride $\geq 2.26 \mathrm{mmol} / \mathrm{L}$ ( $\geq 200 \mathrm{mg} / \mathrm{dL}$ ) among individuals with alcohol pancreatitis as compared to individuals with biliary pancreatitis ( $17.8 \%$ versus $13 \%$ p: 0.24$)$.

It is generally believed that a serum triglyceride (TG) level of more than $11.3 \mathrm{mmol} / \mathrm{L}(1000 \mathrm{mg} / \mathrm{dL})$ is needed to precipitate AP, the reduction of which to levels well below $11.3 \mathrm{mmol} / \mathrm{L}$ is often preventative [7]. Animal studies showed that HTG intensifies the course of both edematous and necrotizing pancreatitis [11]. During the occurrence of AP, 
due to the body's stress response, serum catecholamine, and glucagon levels as well as lipase activity are increased, leading to accelerated break down of fat tissue with subsequent release of TG and increase in serum lipid concentrations [10].

We observed that group 1 had more patients with biliary pancreatitis $(29 \%$ versus $21 \%, p$ : 0.001$)$, which was likely due to the presence of more females (47\% versus 32\%) in this group consistent with the epidemiological studies that showed gallstones are more common in females [17-19]. Group 2 consisted of more male patients (68\% versus 53\% in group 1) and more cases of alcoholic pancreatitis (34\% versus $32 \%$ in group $1, p: 0.001$ ) were seen likely because males are more likely to abuse alcohol [20]. The prevalence of diabetes mellitus (DM) (45\% versus 29\%, p: 0.001) and elevated hemoglobin Alc $(0.088 \pm 0.028$ versus $0.073 \pm 0.025$, $p: 0.001)$ was higher in the study group, which may represent $\mathrm{DM}$ as a risk factor for worse outcomes in patients with AP.

Patients with a triglyceride level of more than $\geq 2.26 \mathrm{mmol} / \mathrm{L}$ had a lower level of serum sodium $(133.5 \pm 6.2$ versus $135.8 \pm 4.3, p: 0.001)$ and lipase levels (12.2 \pm 1.70 versus $17.3 \pm 1.06, p: 0.017)$. Elevated triglyceride levels can alter routine measurements of sodium and amylase. The excess triglyceride in a serum sample can displace water containing sodium and cause pseudohyponatremia [21]. HTG levels $>5.65 \mathrm{mmol} / \mathrm{L}$ may cause a falsely normal amylase level, likely from HTG interference of the calorimetric reading. Serial dilutions of the serum amylase sample can reduce the triglyceride interference [22].

Hypertriglyceridemia was found to be an independent risk factor for development of acute kidney injury in patients with AP and development of AKI in acute pancreatitis is associated with a higher mortality [23]. We excluded patients with chronic kidney disease and end stage renal disease in our study population to validate these results. Patients with a triglyceride level of $\geq 2.26 \mathrm{mmol} / \mathrm{L}$ had higher creatinine levels on admission $(141.44 \pm 106.1$ versus $77.8 \pm 61.9$, $p$ : 0.001$)$, a higher value of maximum creatinine during the admission $(167.9 \pm 61.9$ versus $97.24 \pm 70.7, p: 0.001)$ and higher incidence of acute kidney injury ( $52 \%$ versus $34.85 \%$, p: 0.001). Pancreatic lipase hydrolyzes excess TG in serum resulting in the accumulation of free fatty acids (FFAs), which are toxic to organ function and TG depositing around kidney tubules is hydrolyzed by pancreatic lipase with production of high levels of toxic FFAs around the renal cells, which may directly impair renal function. The levels of pancreatic enzymes are much higher in glomerulus because of concentration and aggravate the damage of renal function [23].

Early phase of acute pancreatitis is associated with coagulation abnormalities and D-dimer can be used as a clinical parameter that has been shown to predict the severity of acute pancreatitis [24]. A higher D-dimer level was present in patients with triglyceride level of $\geq 2.26 \mathrm{mmol} / \mathrm{L}$ (3942.72 \pm 1379.95 versus $1365.16 \pm 479.15, p: 0.03$ ) consistent with more severe disease and higher rates of complications. Although the mechanism underlying the elevated d-dimer levels is complicated, severe coagulative disorder characterized by the diffuse formation of intravascular microthrombi and activation of fibrinolysis could be the predominant cause of this phenomenon [25].

Approximately 85 percent of patients with acute pancreatitis have acute interstitial edematous pancreatitis characterized by an enlargement of the pancreas due to inflammatory edema. Approximately 15 percent of patients have necrotizing pancreatitis with necrosis of the pancreatic parenchyma, the peripancreatic tissue, or both [26]. Our study found that a triglyceride level of $\geq 2.26 \mathrm{mmol} / \mathrm{L}$ was found to be an independent predictor of developing pancreatic necrosis. The occurrence of pancreatic infection is a leading cause of morbidity and mortality in acute necrotizing pancreatitis. Approximately one-third of patients with pancreatic necrosis develop infected necrosis [26].

According to the revised Atlanta classification of acute pancreatitis, a systemic complication of acute pancreatitis is defined as an exacerbation of an underlying comorbidity. In the Atlanta classification, organ failure is a distinct entity separate from a systemic complication [14]. Pancreatic inflammation results in the activation of a cytokine cascade that manifests clinically as a systemic inflammatory response syndrome (SIRS). Patients with persistent SIRS are at risk for failure of one or more organs. Organ failure (acute respiratory failure, shock, and renal failure) may be transient, resolving within 48 hours in patients with moderately severe pancreatitis, or persistent for $>48$ hours in patients with severe acute pancreatitis [14]. Our study showed that acute respiratory distress syndrome ( $7 \%$ versus $1.45 \% p$ : 0.005 ) was higher in patients with high triglyceride level on admission. Our study also showed that a higher triglyceride level on admission was a predictor that the patient will have a longer hospital stay and is more likely to get admitted to ICU and have a higher length of stay in the hospital.

Recent studies have hypothesized that obesity is associated with worse outcomes in acute pancreatitis due to the release of excessive amounts of fatty acids from lipolysis of fat by pancreatic lipases $[10,27]$. In our study, the BMI of both the groups were similar ( $28.7 \pm 7.6$ versus $27.25 \pm 5.9, p: 0.086)$ and we were unable to validate obesity as an independent risk factor associated with worsening of acute pancreatitis. We propose that the increased lipolysis and release of free fatty acids may be secondary to genetic polymorphisms such as the mutations in the lipoprotein lipase gene [28]. Such genetic polymorphisms may place these patients at a higher risk of developing hypertriglyceridemia during acute pancreatitis that in turn leads to direct tissue injury due to mitochondrial damage and upregulation of the inflammatory cascade predisposing to multi-organ failure $[10,27]$. The rapid increase in the free fatty acids has various effects. They damage platelets and vascular endothelium in microcirculation and are associated with an increase in viscosity leading to tissue ischemia and damage of pancreatic acinar cells. Hence, a vicious cycle begins in which acute pancreatitis causes increased lipolysis in genetically predisposed individuals which further damages the pancreas and worsens the severity $[10,27]$.

A few recent reports have attempted to study the effect of triglyceride level on outcomes of pancreatitis and its complications $[10,16,23,27]$. Our study has several strengths 
as compared to previous studies. We included all patients with acute pancreatitis irrespective of the etiologies; hence, the results are more widely applicable. Our sample size was larger as compared to some previous studies. We described individual complications as compared to organ failure as a single entity hence providing a more detailed analysis of the complications that are associated with a higher triglyceride level in acute pancreatitis. Due to the same reason, we were also able to validate the results of previous studies that showed that a higher triglyceride level is associated with increased incidence of AKI [23] and pancreatic necrosis [11, 16].

In summary, a $\mathrm{TG} \geq 2.26 \mathrm{mmol} / \mathrm{L}$ on admission in acute pancreatitis is an independent predictor of developing local and systemic complications (organ failure), hospital length of stay, admission to ICU, and the ICU LOS. High plasma TG level may be one of the independent risk predictors of severe AP. However, our study had limitations due to its retrospective design and further research is needed to validate TG as a single predictor of severity.

\section{Core Tip}

Many predictive models have been developed to identify patients at increased risk for morbidity and mortality from acute pancreatitis. In this retrospective study, we aimed to study the serum triglyceride level within 24 hours of admission as a simple marker that can predict the development of complications (local and systemic) and the need for admission to ICU among patients admitted with acute pancreatitis. The ability to predict the severity of acute pancreatitis can help identify patients at increased risk for morbidity and mortality, therefore helping clinicians to make an early decision to triage these patients to intensive care units as well as selection of patients for specific interventions.

\section{Institutional Review Board Statement}

This study was reviewed and approved by the Institutional Review Board of the Bronx Lebanon Hospital Center (IRB Approval no. 021215 04).

\section{Data Sharing Statement}

Technical appendix, statistical code, and dataset are available from the corresponding author (Hassan Tariq) at Htariq@bronxleb.org. Informed consent was not obtained but the presented data are anonymized and risk of identification is low. No additional data are available.

\section{Biostatistics Statement}

Richard Peralta M.D. and Hassan Tariq M.D. from Bronx Lebanon Hospital Center reviewed the statistical methods of this study.

\section{Consent}

Informed consent was not obtained because this study is a retrospective analysis of the clinical data collected after treatment course was completed. This study gives rise to minimal risk to the patients. In this study, the patient's clinical data collection and analysis, writing papers, and papers from all over the research process were managed in secret for personal information (such as anonymized medical records). In addition, Institutional Review Board of the Bronx Lebanon Hospital Center approved that this study has exemption from the informed consent.

\section{Disclosure}

All authors certify that they have no affiliations with or involvement in any organization or entity with any financial interest or nonfinancial interest in the subject matter or materials discussed in this paper.

\section{Conflict of Interests}

The authors declare that they have nothing to disclose.

\section{Authors' Contribution}

Hassan Tariq and Vinaya Gaduputi were involved in study concept and design; Hassan Tariq and Richard Peralta did the data analysis and interpretation; Hassan Tariq, Vinaya Gaduputi, and Naeem Abbas wrote the paper; Phyo Thet, Tin Zaw, and Shirley Hui were involved in the acquisition of data and statistical analysis; Sridhar Chilimuri and Suresh Kumar Nayudu did critical revision of the paper for important intellectual content; all authors read and approved the final paper.

\section{References}

[1] P. G. Lankisch, M. Apte, and P. A. Banks, "Acute pancreatitis," The Lancet, vol. 386, no. 9988, pp. 85-96, 2015.

[2] A. F. Peery, E. S. Dellon, J. Lund et al., "Burden of gastrointestinal disease in the United States: 2012 update," Gastroenterology, vol. 143, no. 5, pp. 1179-1187.e3, 2012.

[3] P. J. Fagenholz, C. F.-D. Castillo, N. S. Harris, A. J. Pelletier, and C. A. Camargo Jr., "Increasing United States hospital admissions for acute pancreatitis, 1988-2003," Annals of Epidemiology, vol. 17, no. 7, pp. 491.el-491.e8, 2007.

[4] V. K. Singh, T. L. Bollen, B. U. Wu et al., "An assessment of the severity of interstitial pancreatitis," Clinical Gastroenterology and Hepatology, vol. 9, no. 12, pp. 1098-1103, 2011.

[5] H. C. van Santvoort, O. J. Bakker, T. L. Bollen et al., "A conservative and minimally invasive approach to necrotizing pancreatitis improves outcome," Gastroenterology, vol. 141, no. 4, pp. 1254-1263, 2011.

[6] J. A. Windsor, "Search for prognostic markers for acute pancreatitis," The Lancet, vol. 355, no. 9219, pp. 1924-1925, 2000.

[7] P. P. Toskes, "Hyperlipidemic pancreatitis," Gastroenterology Clinics of North America, vol. 19, no. 4, pp. 783-791, 1990.

[8] M. R. Fortson, S. N. Freedman, and P. D. Webster III, "Clinical assessment of hyperlipidemic pancreatitis," The American Journal of Gastroenterology, vol. 90, no. 12, pp. 2134-2139, 1995.

[9] J. Scherer, V. P. Singh, C. S. Pitchumoni, and D. Yadav, "Issues in hypertriglyceridemic pancreatitis: an update," Journal of Clinical Gastroenterology, vol. 48, no. 3, pp. 195-203, 2014. 
[10] L. Cheng, Z. Luo, K. Xiang et al., "Clinical significance of serum triglyceride elevation at early stage of acute biliary pancreatitis," BMC Gastroenterology, vol. 15, article 19, 2015.

[11] L. H. Deng, P. Xue, Q. Xia, X. N. Yang, and M. H. Wan, "Effect of admission hypertriglyceridemia on the episodes of severe acute pancreatitis," World Journal of Gastroenterology, vol. 14, no. 28, pp. 4558-4561, 2008.

[12] D. A. Lindberg, "Acute pancreatitis and hypertriglyceridemia," Gastroenterology Nursing, vol. 32, no. 2, pp. 75-82, 2009.

[13] D. Preiss, "Triglyceride levels, pancreatitis and choice of lipidmodifying therapy," Expert Review of Gastroenterology \& Hepatology, vol. 7, no. 3, pp. 193-195, 2013.

[14] P. A. Banks, T. L. Bollen, C. Dervenis et al., "Classification of acute pancreatitis-2012: revision of the Atlanta classification and definitions by international consensus," Gut, vol. 62, no. 1, pp. 102-111, 2012.

[15] W. Gao, H. X. Yang, and C. E. Ma, "Correction: the value of BISAP score for predicting mortality and severity in acute pancreatitis: a systematic review and meta-analysis," PLoS ONE, vol. 10, no. 10, Article ID e0142025, 2015.

[16] Y. Zeng, W. Zhang, Y. Lu, C. Huang, and X. Wang, "Impact of hypertriglyceridemia on the outcome of acute biliary pancreatitis," The American Journal of the Medical Sciences, vol. 348, no. 5, pp. 399-402, 2014.

[17] A. F. Attili, N. Carulli, E. Roda et al., "Epidemiology of gallstone disease in Italy: prevalence data of the Multicenter Italian Study on Cholelithiasis (M.I.COL.)," American Journal of Epidemiology, vol. 141, no. 2, pp. 158-165, 1995.

[18] K. R. Maurer, J. E. Everhart, T. M. Ezzati et al., "Prevalence of gallstone disease in Hispanic populations in the United States," Gastroenterology, vol. 96, no. 2, part 1, pp. 487-492, 1989.

[19] R. E. Sampliner, P. H. Bennett, L. J. Comess, F. A. Rose, and T. A. Burch, "Gallbladder disease in pima indians. Demonstration of high prevalence and early onset by cholecystography," The New England Journal of Medicine, vol. 283, no. 25, pp. 1358-1364, 1970.

[20] D. S. Hasin, F. S. Stinson, E. Ogburn, and B. F. Grant, "Prevalence, correlates, disability, and comorbidity of DSMIV alcohol abuse and dependence in the United States: results from the national epidemiologic survey on alcohol and related conditions," Archives of General Psychiatry, vol. 64, no. 7, pp. 830-842, 2007.

[21] J. M. Howard and J. Reed, "Pseudohyponatremia in acute hyperlipemic pancreatitis. A potential pitfall in therapy," Archives of Surgery, vol. 120, no. 9, pp. 1053-1055, 1985.

[22] R. W. Fallat, J. W. Vester, and C. J. Glueck, "Suppression of amylase activity by hypertriglyceridemia," The Journal of the American Medical Association, vol. 225, no. 11, pp. 1331-1334, 1973.

[23] C. Wu, L. Ke, Z. Tong et al., "Hypertriglyceridemia is a risk factor for acute kidney injury in the early phase of acute pancreatitis," Pancreas, vol. 43, no. 8, pp. 1312-1316, 2014.

[24] L. Ke, H. B. Ni, Z. H. Tong, W. Q. Li, N. Li, and J. S. Li, "Ddimer as a marker of severity in patients with severe acute pancreatitis," Journal of Hepato-Biliary-Pancreatic Sciences, vol. 19, no. 3, pp. 259-265, 2012.

[25] C. M. Cuthbertson and C. Christophi, "Disturbances of the microcirculation in acute pancreatitis," The British Journal of Surgery, vol. 93, no. 5, pp. 518-530, 2006.

[26] P. A. Banks and M. L. Freeman, "Practice Parameters Committee of the American College of G. Practice guidelines in acute pancreatitis," The American Journal of Gastroenterology, vol. 101, no. 10, pp. 2379-2400, 2006.

[27] H. Nawaz, E. Koutroumpakis, J. Easler et al., "Elevated serum triglycerides are independently associated with persistent organ failure in acute pancreatitis," American Journal of Gastroenterology, vol. 110, no. 10, pp. 1497-1503, 2015.

[28] Y. T. Chang, M. C. Chang, T. C. Su et al., "Lipoprotein lipase mutation S447X associated with pancreatic calcification and steatorrhea in hyperlipidemic pancreatitis," Journal of Clinical Gastroenterology, vol. 43, no. 6, pp. 591-596, 2009. 


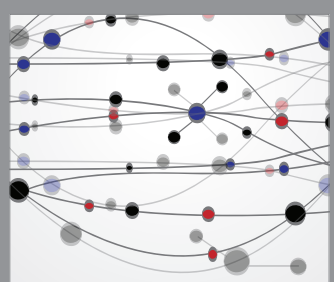

The Scientific World Journal
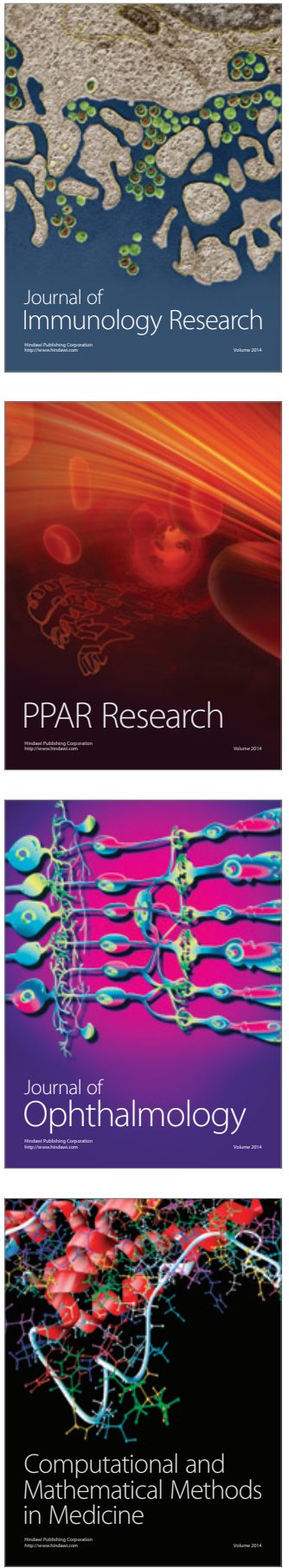

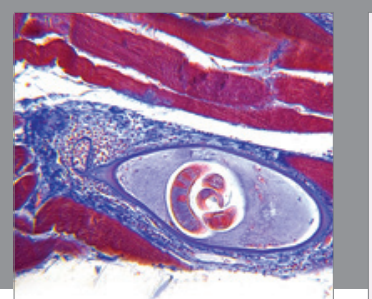

Gastroenterology Research and Practice

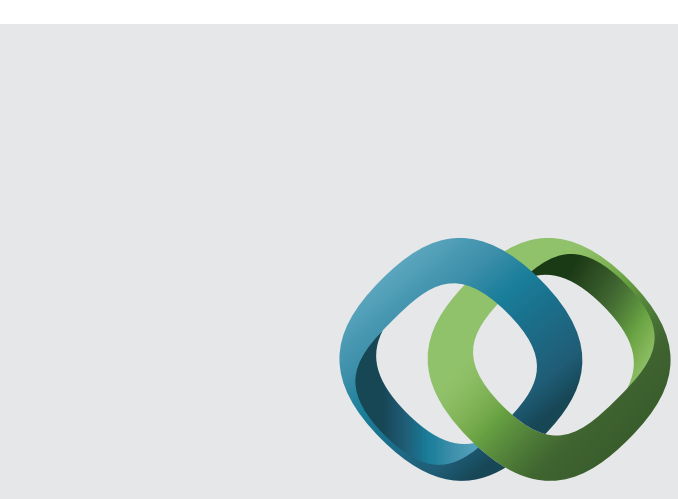

\section{Hindawi}

Submit your manuscripts at

http://www.hindawi.com
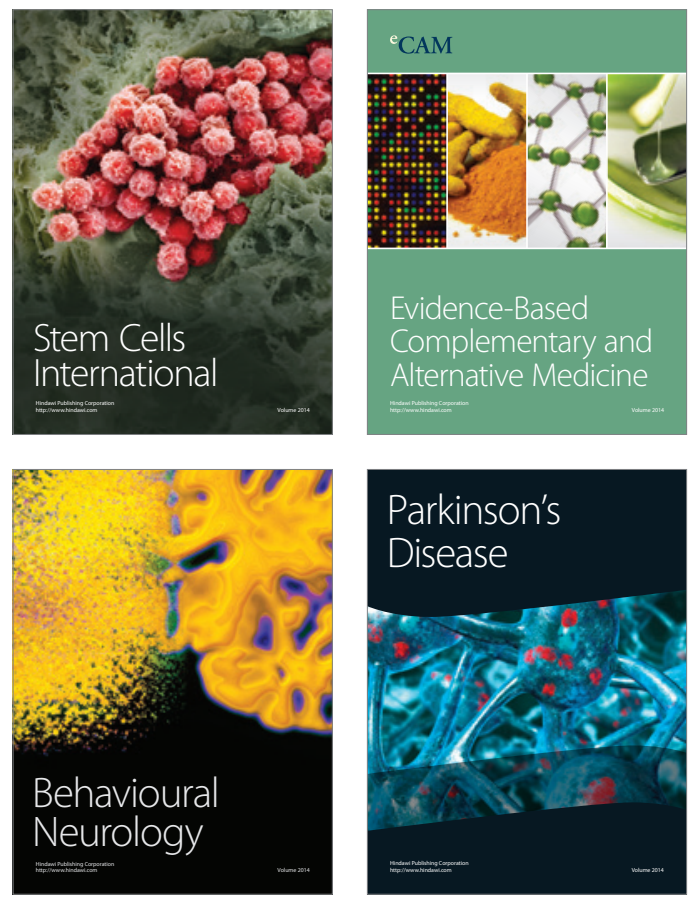
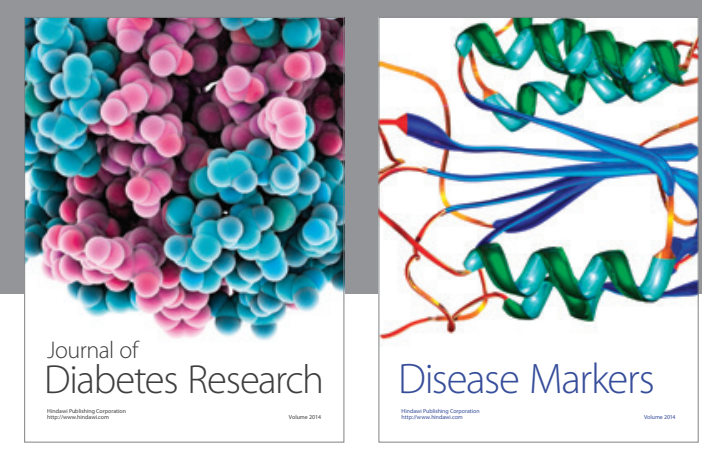

Disease Markers
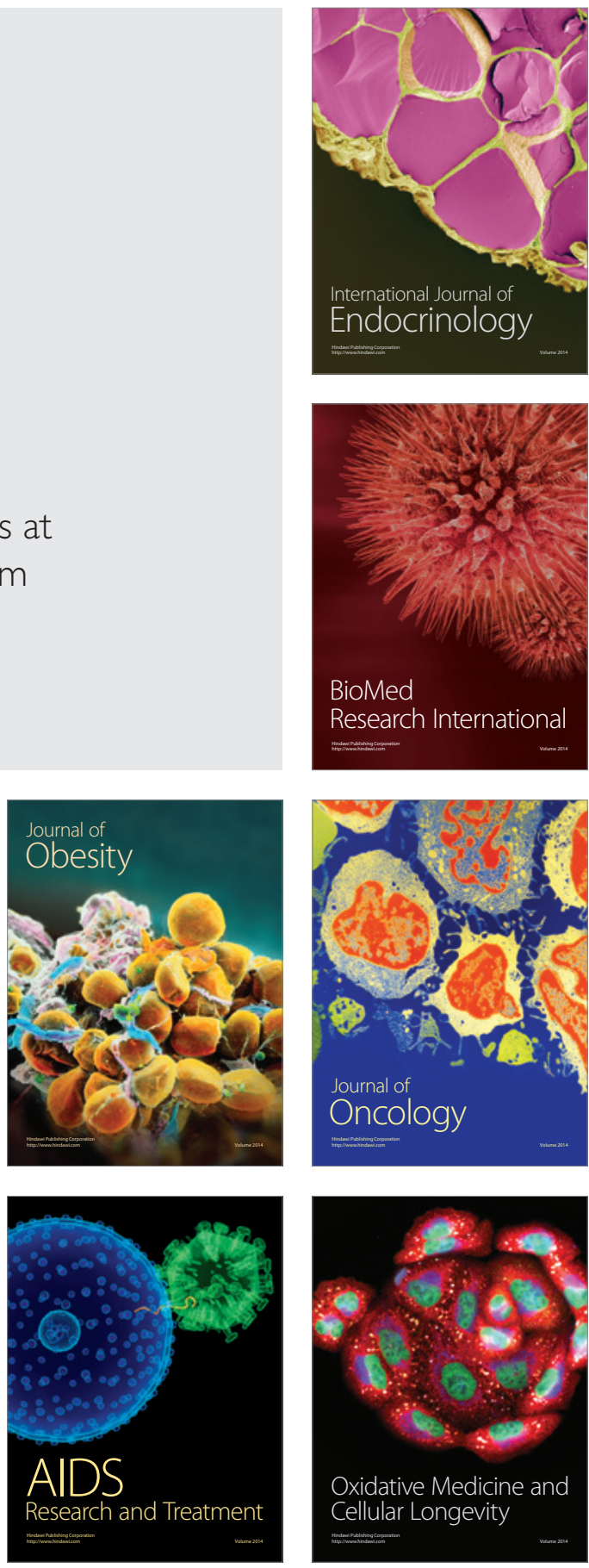